\title{
PROJETOS DE (RE)MODELAÇÃO NACIONAL NO ROMANTISMO
}

Marcelo Chiaretto UFMG

RÉSUMÉ

Ce travail cherche à démontrer la différence entre le romantisme allemand original et le mouvement romantique brésilien et latin, par rapport aux projects de (re)formation national. 
Quando a história de um país não existe exceto em documentos incompletos e esparsos, em vagas tradições que têm que ser compiladas e julgadas, o método narrativo é obrigatório. E qualquer um pode citar uma história geral ou particular que comece desta forma.

Andrés Bello

Ao se considerar a história das nações modernas (e suas respectivas manifestações artísticas), a tensão entre dominadores e dominados é constante e, de certa forma, imprescindível. A imposição do continuum (a histoire ou "história dos dominadores" já referida por Walter Benjamim') choca-se com a existência das minorias que, enquanto resistência, buscam compor a "outra história" (a tradição do descontinuum), recurso em si capaz de problematizar a suposta homogeneidade nacional.

Quando buscam contar a história dos marginalizados ou a história do "outro" que perturba a coesão, as minorias procuram intentar contra o caráter simbólico e, de certa maneira, frágil dessa coesão. Bhabha ${ }^{2}$ diz a respeito:

To write the story of the nation demands that we articulate that archaic ambivalence that informs modernity. We may begin by questioning that progressive metaphor of modern social cohesion - the many as one - shared by organic theories of the holism of culture and community, and by theorists who treat gender, class, or race as radically 'expressive' social totalities."

De acordo com o mesmo autor, o metafórico the many as one, sedimentador, totalizador e orgânico, sofre a intervenção de um metonímico less than one. Este estabeleceria uma ruptura recuperável na coesão, um espaço mínimo que possibilitaria a expressão das minorias a partir de uma perspectiva da singularidade. A minoria seria evocada e o todo sedimentado do the many as one receberia uma provocação, sem que esse todo fosse desfeito. A grande conseqüência seria a manifestação das minorias enquanto mantenedoras de singularidades, mas sem que se coloquem de forma superior, ou seja, o todo é provisoriamente provocado.

1. BENJAMIN, 1987.

2. BHABHA, 1990

3. Op. cit. p. 294.
Tal ameaça se constitui, de acordo com o autor, enquanto performance, como uma transitória encenação.

A manifestação em termos de arte literária do "outro" que perturba a coesão nacional na perspectiva da singularidade pode ser vista como uma das propostas principais de um movimento surgido na Alemanha nos fins do século XVIII, o Sturm und Drang. O movimento, primeira corrente romântica ampla na Europa e responsável pelo surgimento do romantismo universal, buscou romper com um ideal clássico de nação alemã a partir da valorização e expressão das diferenças culturais. Rompendo fronteiras e influenciando boa parte das expressões artísticas do período, as propostas do movimento, no que se refere à remodelação nacional, surtiram um especial efeito considerando-se os romances de fundação na América Latina.

A análise das propostas do movimento, como também sua recepção e aplicação em terras da América Latina (especificando-se o Brasil), tendo como ponto de partida e exemplificação a exposição inicial de Bhabha serão os objetivos desse trabalho.

\section{TÍPICO X CARACTERÍSTICO}

Segundo Hobsbawm, “antes de 1884 , a palavra nación significava simplesmente o 'agregado de habitantes de uma província, de um país ou de um reino"”, ${ }^{4}$ ou seja, não apresentava uma correlação com o conceito de nação moderna. Para o mesmo autor:

Podemos aceitar que, em seu sentido moderno e basicamente político, o conceito de nação é historicamente muito recente. De fato, outro monumento lingüístico, o New English Dictionnary, já sublinhava isso ao indicar, em 1908, que o velho significado da palavra contemplava principalmente a unidade étnica, embora seu uso recente indicasse mais 'a noção de independência e unidade política.'

Conclui-se que na época do Sturm und Drang, fins do século XVIII, o conceito de nação não correspondia ao moderno. No entanto, há de se considerar o fato de que, embora não havendo correspondência direta,

\section{HOBSBAWM, 1990. p.27}

5. Op. cit. p.30. 
o que os primeiros românticos chamavam de nação já indicava claramente para o vindouro conceito moderno. Ao buscar uma ruptura com a universalização e coesão impostas pelo ideal clássico de nação, buscavam estabelecer um espaço nesse todo para a manifestação das diferenças culturais:

A língua, da mesma forma como o indivíduo humano e a nação, passa por um desenvolvimento orgânico. Como eles, nasce, amadurece, definha. Tais concepções baseiam-se numa visão vegetativa da definha. Tais concepções baseiam-se numa visão vegetativa da
História, organismo que se nota ainda nas especulaçóes de Spengler. A singularidade vegetativa de cada povo, diferenciado por clima, geografia, gênio étnico, não admite a imposição de leis e cânones universais (na arte e na literatura). Da concepção de uma 'alma do povo' singular nasce toda uma tradição romântica que se manifestará nas pesquisas folclóricas, nas ciências históricas, lingüística etc do os clássicos, exalta a pluralidade dos povos, cuja diferenciação possibilita o grande acorde da orquestra da humanidade.

Nota-se a preocupação em expressar uma nação desterritorializada, reflexo da ênfase dada à história heterogênea dos povos. Ao movimento romântico repugna a ênfase ao típico nas variações de expressão artística. A perspectiva da singularidade empreendida no movimento procura destacar não apenas o todo concreto como resultado da determinação de variáveis biológicas e étnico-históricas, mas também o gênio original do artista:

Na medida, porém, em que a razão não é considerada valor supremo, realçando-se as forças emocionais e a sensibilidade imponderável do homem, como tais subjetivas e de irredutível variedade, individualismo tende a tornar-se 'organicista': a igualdade essencial, verificável somente através de operaçōes analíticas de abstraçăo, negada, ou, pelo menos, dei negada, ou, pelo menos, deixa de ser valorizada em sentido positivo; em contrapartida é acentuada a singularidade da pessoa concreta, inseparável do contexto histórico e nacional.?

Pode-se notar uma correlação com as palavras de Bhabha. Neste caso, o the many as one representaria a metáfora da nação sedimentada buscada pelo ideal clássico, enquanto que o less than one surgiria como metonímia de interrupção ou intervenção "romântica" na metáfora

6. ROSENEELD, 1993. p.67.

7. Idem. p. 152. totalizadora, com vistas à valorização e ênfase nas minorias. ${ }^{8} \mathrm{O}$ ponto destoante estaria na forma de intervenção: para Bhabha, a intervenção das minorias no todo homogêneo da nação moderna não passaria de uma performance, assim mesmo negociada, estabelecedora de uma tensão; enquanto que na intervenção empreendida pelos românticos em nome das minorias existe radicalismo e ruptura real.

\section{AMÉRICA LATINA - BRASIL}

A aplicação dos ideais de nação firmados pelo movimento alemão do Sturm und Drang resultou em duas perspectivas diferenciadas. Enquanto que, no mundo europeu, deu origem a movimentos a favor da expressão artística das minorias (vide, por exemplo, no âmbito inglês, a recuperação do medievalismo escocês, e na França, a revalorização do provençal), na América, mais especificamente na América Latina, deu origem a um número considerável de romances de fundação nacional. Há de se considerar aqui, antes de tudo, o claro primitivismo em relação aos conceitos de estado e nação presentes neste território, ao se comparar com a Europa, onde, segundo Hobsbawm, ${ }^{9}$ já poderia se observar uma "identificação nacional natural". Podendo-se concluir, assim, pela não existência dessa identificação nos países da América Latina, os romances fundacionais passam então a representar um valioso papel na preparação de projetos nacionais.

A construção do nacional a partir do cânone romântico na América Latina apresentou-se com um aparato amplamente manipulador em termos políticos. Ao escritor cabia a função de instituir e legitimar programas e conquistas políticas, e de fazê-lo de forma o menos filosófica (ou digna de reflexões) possivel. Notem-se as palavras de Costa Lima: ${ }^{10}$

O papel concedido às 'grandiosas cenas nacionais' nâo derivava de uma mera sujeição ao cânone romântico, de uma declarada imitação da Europa, menos verdadeira que oriunda da preguiça dos pesquisadores. Aquele papel é, ao invés, produto de um programa centralmente político: revelar a particularidade da nação a que o escritor,

8. Note-se a busca dos romônticos pela expresssōo dos lieds populares em controposiçōo ò expresssão da herança ocidental grecco-

9. HOBSBAWM, op. cit. p.27.

10. LIMA, 1986. p.152-153. 
com sua pena, ajuda a constituir. Não é tampouco particularidade que se ressalta para que, então, sobre ela, se desenvolva a autoreflexividade. Muito ao contrário. Essa auto-reflexividade exigiria um público leitor capaz de recebê-la e desenvolvê-la por sua conta própria, e isso seria tanto uma pretensão historicamente descabida, quanto um modo de provocar a dispersão de interesses e atenções.

O movimento romântico originalmente alemão ganharia assim um caráter pragmático, ou seja: seria respeitado e seguido apenas no que se apresentava de conveniente à classe política dominante na América Latina. Visava-se sempre dar ao escritor uma função orientada para os objetivos políticos da classe:

O privilégio concedido à observação da natureza continha um duplo e contraditório efeito: (a) visava a fazer com que o escritor se integrasse no projeto de autonominação da pátria; (b) supunha que esta era a maneira de tornar-se o intelectual um ser útil. O primeiro propósito, insistamos, não era decorrente apenas de uma opção romântico-liberal, mas resultante do próprio estado de sociedade latino-americana. 11

Cabia a tais escritores a preparação de projetos nacionais em suas profissōes, ou seja, na escrita de romances. Doris Sommer, em artigos enfocando as ficções fundacionais na América latina, alerta para o caráter alegórico dessas ficções:

Os nacionais latino-americanos são quase infalivelmente histórias de amantes desventurados que representam regiões, raças, partidos ou interesses econômicos específicos. Sua paixão pela união conjugal e sexual transborda sobre o leitor sentimental num movimento que, aparentemente, almeja arrebatar mentes e corações, conquistando adeptos. A linguagem do amor, especificamente da sexualidade produtiva do lar, é notavelmente coerente e fornece veículo para uma pronsolidação nacional aparentemente não violenta, após longas guerras consolidaçáo nacional apar
revolucionárias e civis.

Esse romantismo sob o jogo das conveniências, resultante químico de um Sturm und Drang em combinação com política latinoamericana, em terras brasileiras deu origem a romances fundacionais famosos onde a conciliação e posterior miscigenação das raças foram amplamente difundidas em favor dos "novos projetos da nação":

11. LIMA, op. cit. p. 155

12. SOMMER, 1989. p. 2-3.
O brasileiro O Guarani (1857) concilia traços mais raciais que regionais. Mas, para fazê-lo, José de Alencar teve que branquear e adaptar ao figurino a população escura do Brasil, substituindo as massas de negros e mulatos por nobres índios nativos. O herói que dá nome a livró é toda a redimível população de pele escura, ilustraca e bastante sentimental o bastante para se submeter a s senhora branca. (...) Como solução retórica para as crises nesses romances-países, a miscigenação é freqüentemente a imagem para a pacificação do setor 'primitivo' ou 'bárbaro'.

Mas por vezes essas imagens codificadas em cores representam facções antagônicas de uma elite crioula, de tal modo que as alianças produtivas anunciadas pela alquimia racial podem acabar tendo menos prer com relaçōes de raça do que com flertes políticos entre brancos 'liberais' e "conservadores'.

Depreende-se daí uma contradição perversa: os ideais românticos originais buscavam valorizar as diferenças culturais, proporcionando espaço para a manifestação de todos - seria então totalmente contra a miscigenação por sua decorrente massificação e descaracterização das raças. No entanto, para o romantismo brasileiro (ou latino, pois têm as mesmas idéias) aqui representado por um de seus maiores artífices, tal procedimento seria importante como forma de anular a diferença e assim construir um sonho "horizontal e fraterno de identidade nacional".

Sommer se remete também a outro idílio brasileiro onde índios e europeus "aprendem a se amarem uns aos outros": Iracema (1865), do mesmo José de Alencar, onde uma princesa índia tem um filho mestiço com um aventureiro branco. Outro exemplo não lembrado por Doris Sommer do mesmo período romântico brasileiro é Gonçalves Dias: sua busca pelo realce ao índio brasileiro acaba por defini-lo enquanto ser esquizofrênico, pois apresenta estilo de vida indígena, mas tem caráter e ideais europeus. É o índio europeizado - novo ideal de mestiçagem. Sobre esse ideal, Sommer faz o seguinte relato:

O ideal de 'mestizaje', pejorativamente traduzido por miscigenação, era baseado, na realidade, de raças mestiças para as quais os positivistas imputaram diferentes virtudes e fracassos, que tinham de ser amalgamados, se qualquer coisa como unidade nacional fosse produzida. Unidade na retórica positivista, não era tanto um conceito políico ou economico cono era biologico. Desde quécrescimento significasse modernização e europeizaçá, os qdeólogos mais Sarmiento) advogaram uma política pautada na imigração branca e na remoção de índios e negros,

13. SOMMER, 1990. P. 81. 


\section{MÉTODOS DE (RE)DEFINIÇÃO NACIONAL}

Benedict Anderson, em Naçăo e consciência nacional, ${ }^{15}$ faz referência à importância dos jornais e dos romances na conformação da figura de nação homogênea a partir das comunidades imaginadas de leitores. Seriam, assim, previsões das futuras nações modernas. De acordo com suas palavras, foi um processo que tomou forma em primeiro lugar entre as elites lingüisticamente homogêneas do Novo Mundo, que se tornaram modelos para os construtores de nação europeus. Sommer relembra esse trecho e conclui:

Talvez não seja demasiado pretensioso, portanto, afirmar que os romances latino-americanos parecem 'corrigir' modelos europeus ou pelo menos realizar seus desejos frustrados. ${ }^{16}$

O movimento romântico acaba por assumir um caráter político possivelmente não imaginado por seus fundadores. Na sua origem, Johann Georg Hamann, Johann Gottfried Herder e, de certa forma, Goethe (quando jovem), Schiller, os irmãos Schlegel e Novalis buscavam exaltar as minorias com a ruptura do the many as one da nação no ideal clássico, estabelecendo assim um método de redefinição nacional. No entanto, o que se vê na fase posterior do movimento (quando as idéias são universalmente difundidas) é uma nova versão, mais pragmática e mais moderna, com vistas ao estabelecimento de um método de definição nacional.

Pode-se concluir, a partir de tudo que já foi mencionado, que o romantismo brasileiro (ou latino), no que se refere aos romances fundacionais, busca legitimar a metáfora antes repudiada do the many as one. Se anteriormente procurava-se contar a história do "outro" que perturbaria a coesão, agora o que se conta são as vantagens da síntese, a síntese que abole a diferença.

\section{0p. cit. p. 85 .}

15. ANDERSON, 1989. p. 34-35.

16. Op. cit. p. 35.

\section{REFERENAIAS BIBLLOGRÁFICAS}

ANDERSON, Beneditc. Naģ̃̃a e consciênncio nocional. Säo Poulo: Ático, 1989.

. BHABHA, Homi K. Dissemintotion: time, narrotive, ond the morgins of the modern notion. In: Mo de Janeiro. Pozzo Tovidade: do.

do revoluşāo oo liberolismo ln: Naşöes e nacionalisma desde 1780

LIMA, Luiz Costo. Sociedode e discusso ficcionol. Rio de Joneiro: Guonoboro, 1986

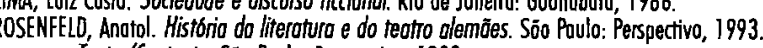

Texto/Contexto, Sōo Paulo: Perspectivo, 1983.

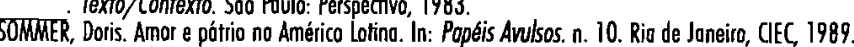

- Irresisitible romonce: the foundational fictions of Latin Americo. Trad. Potricio Fonseco. In: BHABHA, H.K. (Org.). Nation and norrotion. New York. Routledge, 1990. 